\title{
ESTÉTICAS DO ANIMAL-ESTAR
}

ESTHETICS OF ANIMAL-BEING

Olga Kempinska

Universidade Federal Fluminense

Niterói, RJ

\section{Resumo}

Este ensaio é uma leitura do texto de Derrida $O$ animal que logo sou ( $A$ seguir) e uma reflexão sobre os possíveis usos da expressão animal-estar para a descriçáo dos desafios contemporâneos da estética. Assim, ao investigar o desconforto subjetivo envolvido no gesto de ultrapassar a fronteira entre homem e animal, e de desterritorializar o pensamento, o estudo se debruça sobre os efeitos da anulaçáo da distância estética e sobre a exacerbação do componente "sensível" da expressão geral "experiência sensível”. Resultado da falha da domesticação da percepção, relacionado também à atualização das emoçóes e das reaçóes do corpo, o animal-estar do leitor possibilita uma subversão da reflexividade especular redutora.

Palavras-chave: estética; desconstrução; animalidade.

\section{Abstract}

This essay is a reading of Derrida's The Animal That Therefore I Am and a reflection on the possibility of the uses of the expression animal-being for the description of the contemporary aims of esthetics. In analyzing the subjective discomfort involved in the gesture of crossing lines and of deterritorialization of the thinking, the paper investigates the effects of the annulation of the esthetic distance and of the extrapolation of the component "sensible" in the general expression "sensible experience". Because of the failure to provide the domestication of the perception, also related to the importance of emotions and body-reactions, the animal-being of the reader leads to a subversion of the reductive reflexivity.

Keywords: esthetics; deconstruction; animality.

\section{Résumé}

Cet essai est une lecture de L'animal que donc je suis de Derrida et une réflexion sur les usages productifs du mot animal-être pour la description des enjeux contemporains de l'esthétique. Ainsi, en examinant le mal-être subjectif lié au geste de traverser les frontières homme-animal et de déterritorialiser l'acte de penser, l'étude se penche sur les effets de l'annulation de la distance esthétique et de l'exacerbation de l'élément «sensible» dans l'expression «expérience sensible». En résultant du fracas de la domestication de la perception et en mettant en jeu des émotions et des réactions corporelles, l'animal-être du lecteur permet aussi une subversion de la réflexivité spéculaire réductionniste.

Mots-clés: esthétique; déconstruction; animalité. 
Estava passeando pela aleia de eucaliptos quando, de repente, de trás de uma árvore, surgiu uma vaca. Parei e olhamo-nos olhos nos olhos. Sua vaquidade surpreendeu a tal ponto a minha humanidade - o momento em que nossos olhares se encontraram foi bem tenso - que fiquei confuso como homem, isto é, no meu gênero humano. Um sentimento estranho e quem sabe pela primeira vez por mim experimentado - essa vergonha de um ser humano perante um animal. Deixei que ela me olhasse e me visse - isso nos colocava em pé de igualdade - pelo que me tornei também animal - mas um animal estranho, diria eu até proibido (GOMBROWICZ, 1997: 366).

A cena de troca de olhares com a vaca, descrita no diário argentino de Gombrowicz numa quarta-feira de 1958, faz entrever uma semelhança irresistível com a cena da troca de olhares de Derrida com sua gata. $\mathrm{O}$ mesmo tom autobiográfico, a mesma sensação de ser visto por um animal, a mesma surpresa, a mesma vergonha, o mesmo mal-estar dos limites baços do humano: "Frequentemente me pergunto, para ver, quem sou eu - e quem sou eu no momento em que, surpreendido nu, em silêncio, pelo olhar de um animal, por exemplo os olhos de um gato, tenho dificuldade, sim, dificuldade de vencer um incômodo" (DERRIDA, 2002: 15).

Todavia, diferentemente de Derrida, que a partir da experiência de ser pego de surpresa pelo olhar de um animal desdobra uma escrita da diferença homem/animal, Gombrowicz "enjoou-se” logo da vertigem e rapidamente - já na semana seguinte, como lemos no diário - decidiu largar o tema: "Confesso - isso me deixa enjoado. Não quero pensar sobre isso. E não gosto, praticamente não aguento aventurar-me com o pensamento para além do reino humano" (GOMBROWICZ, 1997: 370). E por mais que no diário gombrowicziano ainda numerosas vezes os animais em uma diversidade considerável - cavalo, cachorro, mosca, besouro - surjam em cenas permeadas pelo pathos, como viventes que sofrem, essa escrita do eu que cede a todos os ímpetos da compaixão há de evitar a "aventura” antropológica e filosófica no outro "reino". É como se o emigrante Gombrowicz, que sabia se desesperar com o suplício dos besouros derrubados na areia e queimados vivos pelo sol - as páginas dedicadas à descrição de tentativas de virá-los de volta para salvá-los contam entre as mais emocionantes de todo o diário -, e até mesmo com a lentidão da agonia de uma mosca, tivesse chegado muito perto de algo para rapidamente recuar.

Bem perto, de fato, pois sua recusa de se aventurar no outro "reino", de subverter a unidade de mais um território e de confundir mais uma fronteira - depois da nacional, da geracional e da genérica -, é expressa em polonês através do verbo "nudzic": "1 "tomnienudzi", "isso me dá tédio", mas também

\footnotetext{
${ }^{1}$ Em polonês, o verbo "nudziç" significa "entediar". Mas a mesma raiz da palavra "nuda" (tédio, enfado) surge no substantivo plural "nudności" (enjoo, náusea).
} 
“isso me dá nojo", "isso me deixa enjoado". Não se trata aqui de uma espécie de animal-estar derridiano? O teor dessa vacilação seguida de recuo - dessa falta de disposição moral e dessa indisposição física - não passa, aliás, despercebido aos olhos do próprio Gombrowicz: "Anotemos isso, pois quem sabe se não se trata aqui de uma das mais importantes particularidades da minha humanidade: surge em mim uma resistência, tomando forma de enfado, de enfaro" (GOMBROWICZ, 1997: 370).

Questão de "reino", de classe e de família, apesar de tudo? Faria Gombrowicz parte daquele "meio humano" que, como o proprietário da gata Saha, "se proíbe de reconhecer e até mesmo de conceber seus parentescos animais" (COLETTE, 2004: 74)? Ou então talvez algo tenha faltado em sua cena com a vaca? Contudo, Gombrowicz não estava nu perante o animal. Tampouco compartilhou com aquele bicho sua intimidade cotidiana - a vaca não o seguiu nos caminhos diários, menos ainda no caminho até o banheiro. Derrida reencontra a paixão no enjoo porque se deixa seguir: "Ao despertar, a gata me segue ao banheiro reclamando seu café da manhã, mas exige deixar o dito banheiro desde que ele (ou ela) me vê nu, disposto a outra coisa completamente diferente e decidido a fazer esperar" (DERRIDA, 2002: 31-32). O mal-estar, a in-disposição cuja intensidade levará aos desdobramentos poéticos e filosóficos, aflora no texto derridiano não como um acidente único (a vaca de Gombrowicz que surgiu de trás de uma árvore - no passado), mas, em meio à experiência de um convívio diário, de uma frequentação mútua, de uma confusão contínua de territórios cuja escrita recorre à atualidade do tempo presente: "Aliás trata-se de uma cena que se reproduz todas as manhãs" (DERRIDA, 2002: 31). O interesse e a paixão - aquela "disposição" e aquela disponibilidade que haviam faltado a Gombrowicz - emergem em meio à atualidade da cena matinal da estranha promiscuidade rica em detalhes: "a última vez que cruzei o olhar de uma gata-gato que parecia implorar-me, pedindo-me claramente que lhe abrisse a porta para sair, sem esperar, o que faz frequentemente, por exemplo quando me segue ao banheiro e logo se arrepende" (DERRIDA, 2002: 31). Como notou Colette, que também se deixou seguir por animais em seus caminhos diários e em seus textos, "em conviver com (fréquenter) o gato, corre-se o risco apenas de enriquecer-se" (COLETTE, 2011: 46). Frequentemente, com frequência, seguidamente, Derrida convive com o gato e com a pergunta, arriscando-se, assim, no outro reino e correndo o risco de se enriquecer.

É a precisão dos gestos manifesta em $O$ animal que logo sou ( $A$ seguir) na evocação da proximidade cotidiana com a gata - segurar a porta do banheiro para a gata entrar, abrir a porta para a gata sair -, que suscita um parentesco inesperado com a escrita do japonês Junichiro Tanizaki. Não apenas em virtude 
do amor que Tanizaki tinha das gatas, que, como relata sua tradutora brasileira Leiko Gotoda - após ter ouvido a anedota de sua mãe imigrante, irmã mais nova do escritor -, fazia com que se dirigisse à sua preferida com a forma honorífica O-Tama-San, Senhora Bola, mas também por ter escrito A Chave (dos diários) e o Diário de um velho louco, romances confessionais que brincam com a escrita em primeira pessoa e que colocam em cena a velhice impudica. Animalidade, humanidade, "minha paixão pelo animal desperta nessa idade" (COLETTE, 2011: 44). E talvez ainda também por ter transportado a reflexão sobre a estesia para o território do banheiro no ensaio Em louvor da sombra: "Segundo dizem, o escritor Soseki Natsume ${ }^{2}$ contava as idas matinais ao banheiro entre os prazeres de sua vida, e delas auferia êxtase fisiológico" (TANIZAKI, 2007: 12). Pois a latrina tradicional japonesa, que é no ensaio de Tanizaki um dos primeiros exemplos de comparaçáo entre a estética oriental e a estética do outro, a ocidental - uma porta, uma entrada no tema e na reflexão -, não é vista como um espaço deletério, "impróprio até para ser citado em público" (TANIZAKI, 2007: 14) - ou, se for citado, o ser apenas de forma negativa, como o espaço mais útil, logo o mais "feio", por exemplo, como o antiespaço do discurso parnasiano (GAUTIER, 2002: 230). Na cartografia tanizakiana do cotidiano, trata-se, antes, do espaço do início de um dia e também de um início do pensamento - "E pensar começa talvez aî" (DERRIDA, 2002: 57) -, e o banheiro, a latrina na qual não há espelhos, é descrito pelo japonês como permeável a sons animais: homem pode ouvir nesse território poroso da intimidade o fino zumbido de um pernilongo, o cricrilar de grilos e o gorjeio de pássaros.

Gombrowicz escreveu sua recusa de se aventurar para além do reino humano como um tédio-nojo e também como um gesto de fechar a porta: "o quanto antes, volto para a minha casa humana e fecho a porta à chave" (GOMBROWICZ, 1997: 370). Derrida segura a porta, entreabre a porta - do banheiro, da casa do banho, desse território impensável da higiene cotidiana e da evacuação -, espaço estratégico do "reino" humano, no qual o homem se desfaz de suas "impurezas", dispóe dos seus rastros, em particular dos cheiros, "para confundi-los, para apagá-los" (DERRIDA, 2002: 63), e para se distinguir do animal. $\mathrm{O}$ banheiro, sendo o espaço no qual o ser humano desafia diariamente seu corpo natural inimigo, transformando-o em um corpo civilizado, é o lugar da transformação da natureza em cultura. Mas há idades infância, velhice -, há períodos - qualquer indisposição física, na verdade em que a disposição dos rastros e a prática das técnicas do pudor se tornam mais difíceis. Segurar a porta do banheiro e deixar-se seguir por um animal (e por um leitor animal) pela cena da intimidade cotidiana é um gesto ousado, um gesto da escrita de um diário de um velho louco, que, misturando os "rei-

\footnotetext{
${ }^{2}$ Autor, entre outros, da narrativa Eu sou um gato.
} 
nos", entre os quais o da natureza e o da cultura, se coloca a nu: "se eu estou nu aos olhos do gato que me olha da cabeça aos pés, diria eu, apenas para ver, sem se privar de mergulhar sua vista, para ver, com vistas a ver, em direção ao sexo" (DERRIDA, 2002: 16).

Um dos interlocutores da escritora fictícia Elizabeth Costello - mas também de Derrida, de Kafka, da Bíblia, de Descartes e de Nagel - coloca as coisas de uma forma muito crua (e faz isso durante uma refeição): se os animais não têm pudor e "são nus", é porque "não escondem seus excrementos, eles fazem sexo abertamente" (COETZEE, 2003: 85). Uma outra interlocutora brinda os comensais com uma observação mais ríspida ainda: "Animais são criaturas com as quais não fazemos sexo - é assim que os distinguimos de nós mesmos" (COETZEE, 2003: 85). Mas existem tantas ficçóes que desafiam essa distinção ao misturar os reinos e os territórios e ao explorar, por exemplo, casos de triângulos amorosos com animais envolvidos em violências miméticas - Colette, Tanizaki, Highsmith, ${ }^{3}$ o Max, Mon Amour, de Nagisa Oshima -, nos quais o nome do animal se escreve, aliás, como um nome de estrangeiro: Lilly no Japão, Saha na França, Ming nos Estados Unidos. Enfim, existem também "outros" animais, como o gato "cármico" do conto indiano de Anita Nair, narrado no feminino: "Rápido e com carinho, secou o gato. Depois tirou sua camiseta. Sentiu sobre si um par de olhos. Confusa, colocou rápido um corpete"; "A força desse olhar perscrutador endurecia a ponta de seus seios como passas" (NAIR, 2005: 116; 118).

Pela tradução, pela intertextualidade e pela multiplicação de rastros e de "besteiras" - "Que este animal parece falar aqui português e não seja menos tolo por isso, poder-se-ia farejar o rastro disso a partir da primeira questão: 'O animal que eu sou [sigo], fala?” (DERRIDA, 2002: 62-63) - o texto de Derrida aventura-se também a animar o outro sentido, o olfato. Farejar: seguir levado pelo faro, aspirar o cheiro do outro. Ao lado dos poemas que apostrofam um felino e que buscam seu olhar - Baudelaire, Rilke, Buber -, imiscuem-se na leitura do texto de Derrida apóstrofes que animam esse outro sentido ausente da maioria das estéticas: "Ó tu que te apossavas dos travesseiros, / com teu bafo de fígado cru, / onde estás agora?" (ATWOOD, 2013: 17). Ou ainda confissões poéticas das atividades exuberantes desse faro suspeito: "Não sei ser apenas humana / há em mim um camundongo em fuga / e uma doninha farejando sangue" (POŚWIATOWSKA, 2012:341). Um sentido animal, o faro do outro, que, diferentemente da visão, opera pela confusão, precisa da proximidade obscena e obscura, da mistura sem limites nítidos (onde começa um cheiro?), que

\footnotetext{
${ }^{3}$ Refiro-me às seguintes narrativas: COLETTE. La Chatte. Paris: Hachette, 2004; TANIZAKI, Junichiro. Le Chat, son maître et ses deux maîtresses. Trad. Cécile Sakai e Jean-Jacques Tschudin. Paris: Folio Gallimard, 2009; HIGHSMITH, Patricia. Ming's Biggest Prey. In: TESDELL, S. Diana (Ed.). CatSories. New York: A. A. Knopf, 2011: 187-201.
} 
chega a ser um sentido criminoso, representado como sentido de um criminoso no Perfume, de Patrick Süskind. De fato, na estética tradicional o olfato, sempre muito próximo do paladar, fazia pouco sentido humano, apenas "protegendo um organismo através dos avisos sobre substâncias nocivas e venenos" (KORSMEYER, 2004: 89). Seguindo um animal, podemos assim caminhar rumo a uma fruição da intensidade, rumo a outros sentidos, outros territórios e outras estéticas. $\mathrm{O}$ faro desafia a estética com suas noçôes tradicionais de distância, contemplação e resposta, pois o olfato, não sendo especular, impossibilita qualquer frontalidade do confronto olhar-reflexo, pergunta-resposta.

No início do texto derridiano, é, no entanto, no olhar (do homem e da gata) que se inicia a cena de mistura dos territórios: "Para ver, sem ir lá ver, sem ainda tocar nele, e sem lhe dar uma mordida, embora essa ameaça permaneça à flor dos lábios ou na flor ou na ponta da língua" (DERRIDA, 2002: 16). Além do questionamento do risco envolvido na possibilidade da reciprocidade especular do felino, a própria passagem de fronteiras entre homem e animal, aquele gesto de se arriscar nos confins do humano acompanhado de um intenso mal-estar, são descritos como uma emoção especular, uma comoção de segundo grau. O relance do felino suscita em Derrida uma vergonha perante a vergonha, uma "vergonha que enrubesce de ter vergonha" (DERRIDA, 2002: 16). E talvez seja antes de mais nada a quebra da economia confortável da relação especular o que interessa aqui: a incerteza quanto ao sentido do relacionamento com o animal, expressa também através da evocação da dúvida de Montaigne acerca do sentido da reflexividade: quem brinca com quem? - o homem com a gata ou a gata com o homem? Quem olha quem? Quem segue quem? A respeito dessa estranha e incerta reciprocidade, sempre ameaçada pela mera projeção antropomorfizante, Clarice Lispector prefere evocar um "mútuo assassinato" (LISPECTOR, 1998: 135) que emerge do encontro entre os olhos de um búfalo e os olhos de uma mulher mal-amada. A escrita do animal-estar tornase assim um desafio não apenas à comparação reducionista típica das fábulas, que é uma forma de domesticação da representação, mas também àquelas construçóes antropomorfizantes que lançam mão de um ponto de vista do animal (pensemos nos narradores equestres Beleza Negra e Kholstomer), operando com isso mormente um mimetismo da percepção (e da linguagem) humana.

O texto de Derrida evita emprestar uma voz humana ao animal, pois aqui o vislumbre da estranha reciprocidade e a colocaçáo momentânea em pé de igualdade desencadeiam uma incerteza quanto à "natureza" da relação entre homem e animal. Essa experiência da impossibilidade da reduçâo do olhar do outro ao olhar próprio, da subjugação da imagem do outro à imagem própria e, finalmente, do uso dessa imagem para os fins próprios convida a uma leitura interessada de diversas poéticas da suspeita perante a cons- 
trução da especularidade mimética (vejo-me no animal e vejo o animal em $\mathrm{mim}$ ). Trata-se - e proponho aqui uma leitura de textos relativamente recentes da polonesa Wisława Szymborska, da argentina Diana Bellessi e da estadunidense Kimiko Hahn - de poéticas de um animal-estar que trabalham com a construção irônica de cenas dos usos humanos "autorreflexivos" do animal e que praticam um desnudamento das reduçôes antropomorfizantes.

Szymborska, poeta da irônica indiferença - "Devo muito / aos que não amo. (...) A alegria de não ser eu / o lobo de suas ovelhas" (SZYMBORSKA, 2012: 54) -, em um gesto que no primeiro momento parece brincar com a construção narrativa do ponto de vista do animal, dá a voz a um társio no poema que tem como título justamente esse nome interessante de um animal pouco conhecido:

Eu társio filho de társio, neto de társio e bisneto, um animal pequeno, feito de duas pupilas e do restante o mais necessário; por milagre salvo do processamento, pois não dou um prato gostoso, há maiores para as estolas, meus órgãos náo trazem sorte, a música se toca sem meus intestinos; eu társio fico sentado vivo na praça do homem.

(...) (SZYMBORSKA, 1997: 102)

O "társio" ("tarsjusz" em polonês) - nome-armadilha, que me pegou na primeira leitura de surpresa me colocando na cena do discurso de algum santo-filósofo-poeta da Antiguidade - é um pequeno primata do sul da Ásia. Este animal de olhos enormes apresenta-se, no início do texto de Szymborska, como indigno de morte por não ter muita utilidade no "processamento", ou seja, no processo da transformação da natureza em cultura (culinária, moda, religião e música). Mas o monólogo do társio sentado na praça do homem não se limita à denúncia do uso dos animais como matéria-prima e a ironia de Szymborska há de ainda encontrar um novo e inesperado desdobramento. Com efeito, até a inutilidade prática do pequeno animal, transformado agora em representante de uma coletividade de bichos milagrosamente "improdutivos", é aproveitada pelo ser humano que, experto, consegue torná-la útil no nível moral:

e apenas nós poucos, não esfolados,

não tirados dos ossos, não tombados das penas, respeitados em espinhos, escamas, cornos, caninos, e no que ainda cada um tiver 
de esperta proteína,

somos - grande senhor - teu sonho,

que te absolve por alguns segundos.

[...]

(SZYMBORSKA, 1997: 102)

A subversão do uso mimético do animal produz-se no poema de Szymborska graças ao abuso poético dos sentidos possíveis da "utilidade". Não podendo aproveitar a matéria do seu corpo, o homem acaba por transformar o animal em um "sonho" que espelha suas duvidosas qualidades. $\mathrm{O}$ társio torna-se com isso um alimento espiritual para a autoestima do "grande senhor" dos viventes. Podemos ainda espantar-nos aqui com essa colocação em cena mordaz do interesse paradoxal do desinteresse prático, que faz deslizar o pequeno primata para o âmbito inesperado: com sua inutilidade útil, o társio está prestes a se transformar em um animal "estético" por excelência.

Se o "Társio" constrói uma cena grotescamente absurda na qual a destruição que (ainda) não foi perpetrada quase equivale a um gesto de criação, Diana Bellessi serve-se da especularidade mimética para construir uma cena irônica da evolução:

Oh parentes, quatro milhôes

de anos dizem, que vamos nos

erguendo em duas patas e dizem

também, talvez a evolução

já terminou. Podem acreditar

nisso? Se este fosse o modelo

acabado, para que diabos

levar quatro milhôes de anos

erguendo as patas? Mais graça

tivemos entre os galhos [...]

(BELLESSI, 2009: 829)

Ao recorrer ironicamente ao discurso evolucionista após o título "Doktor Darwin" - e notemos a grafia estrangeira do vocábulo "Doktor" - e ao estabelecer uma comunidade irônica dos homens através do vocativo "Oh parentes", o endereçamento poético transforma-se em um trabalho de comparação no qual o espelho devolve ao ser humano um reflexo "ao contrário", invertido e extremamente deceptivo. As qualidades animais (e o poema descreve não apenas a agilidade graciosa de macacos, mas também o canto de baleias e o amor de cachorro) aparecem como "instintos" preciosos perdidos no longo processo da evoluçáo. Essa cena especular comparativa, na qual a direçáo do ato de "seguir" é subvertida, leva ao desejo de se refazer o caminho da evolução ao contrário. Deveríamos nós entâo agora seguir os animais... Interessante 
é ainda que, no final do texto, o homem se encontre tristemente reconduzido a sua própria reflexividade solitária:

Volte

parente, refaça o caminho

e desmintamos este erro

feroz. Falta sentir por outros

o que você aprendeu sozinho

como um anseio de si mesmo

(BELLESSI, 2009: 830)

O uso irônico do discurso evolucionista e uma subversão da comparação reducionista com os animais manifestam-se também no poema de Kimiko Hahn "Sobre borboletas", encontrando aqui uma articulação particularmente violenta:

Apenas a rara borboleta come coisas vivas

a lagarta do Hyposmocoma

tece seda em volta de um molusco

prendendo a concha numa folha

entáo enfia sua cabeça adentro

e come o caramujo vivo.

Um entomologista em Maui

compara esse comportamento doentio

a um lobo que mergulha atrás de ostras.

[...]

(HAHN, 2010: 35)

É através da recorrência do itálico com o qual se escreve o nome científico Hyposmocoma que o texto de Hahn tece uma relação de comparação entre os comportamentos animais e humanos. Esse nome latino, impronunciável em uma primeira leitura, injeta uma língua estrangeira para dentro da matéria do poema escrito em inglês. A língua estrangeira passa, assim, a devastar a língua própria - tal como a lagarta devora o molusco - encontrando seu eco na repetição do nome de uma das ilhas de Havaí, Maui e, ainda, no paralelismo final em " $m$ " que este nome desencadeia com a expressão "minha mãe":

Eu o vejo como uma menininha

que despedaça seu amiguinho

para comer suas entranhas.

Ou uma mãe que dilacera outra mãe

pelo seu filho não nascido.

Ou uma mãe que dilacera sua própria cria 
para soltar o demônio adentro.

Essa fome é menos rara

do que uma borboleta com dentes afiados.

Minha mãe é de Maui.

(HAHN, 2010: 35-36)

Hyposmocoma - e come o caramujo vivo - um lobo que mergulha atrás de ostras: a anomalia gráfica constrói uma série de cenas de violência que justapóem os costumes do animal insólito, pois as borboletas figuram no imaginário humano como uns dentre os mais "inocentes" seres, e as atitudes humanas perversas. Na verdade, a sequência sobre os bichos humanos coloca em cena a violência especificamente feminina, a da menina e a da mãe, que, desmentindo a aparência de brandura, devastam o outro a partir de dentro. Mas observemos que, neste poema, como em geral no volume Toxic Flora, de Hahn, a cena especular na qual o homem se vê no animal é ironicamente construída como uma comparação minuciosa (e maliciosa) com a vida ("doentia") dos insetos.

Em diferentes línguas que, no entanto, acabam todas por recorrer a nomes estranhos e estrangeiros - "társio", "Doktor Darwin", "Hyposmocoma", "Maui" - Szymborska, Bellessi e Hahn constroem cenas poéticas nas quais a comparação entre homem e animal perde o rumo e desencaminha. Esse desencaminhamento se dá por meio de colocaçóes em cena irônicas de discursos que evitam trocas recíprocas de olhares, frequentações cotidianas e colocaçóes em pé de igualdade, e preferem trabalhar antes com as construçôes, sobretudo visuais, de alteridades negativas e de olhares hierarquizados agenciados verticalmente. Assim, a colocação em cena de olhares humanos lançados sobre (pois trata-se aqui de olhares de cima) o társio, os macacos, a baleia, o cachorro e a borboleta, possibilita uma subversão irônica da domesticação presente na representação antropocêntrica dos animais.

Se a reflexividade é uma atividade de risco, observa Derrida, é porque envolve não apenas as atitudes de ver-me no espelho e no outro, mas também a possibilidade de "morder minha língua" (DERRIDA, 2002: 17). Com efeito, quando a comparaçáo perde o rumo, quando a representaçáa se torna indomável, aqueles olhares humanos lançados de cima sobre os animais tingem-se de nuances inegavelmente cômicos. E parece-me que, em Szymborska, Bellessi e Hahn, é sobretudo o efeito humorístico, desencadeado pelas cenas irônicas nas quais as miradas humanas interessadas procuram por animais, que funciona como um corte emocional, comparável ao acidente de morder-se a língua, que rompe a continuidade de um discurso. Pois esses olhares têm um grande potencial risível: tanto a projeçáo narcisista desencadeada pelo társio de enormes pupilas em Szymborska, quanto o espelho às avessas que revela efeitos de uma irremediável involução em Bellessi, e, em Hahn, 
a lupa de entomologista utilizada como um dispositivo ótico para observar em aumento os romances familiares dos bichos humanos. Atingindo emocionalmente o leitor e provocando seu animal-estar, o efeito humorístico dessas colocaçóes em cena irônicas permite uma subversão carnavalesca das "fábulas" comparativas domesticantes.

Diferentemente de Gombrowicz, que o quanto antes retorna ao território seguro da casa humana, Derrida, ao se entregar ao mal-estar do impacto do olhar da gata, recusa a domesticação da percepçáo. Pois, sem poder ser anulado como mero suporte para o refletido, para o reflexo e para a reflexão - e "Tudo o que reflete some. Não vemos o espelho, apenas o que nele se reflete" (RAMOS, 2011: 49) -, o relance da gata derridiana, que segue o olhar mal acordado do filósofo, preserva sua materialidade poética. O olhar do felino, descrito como um olhar "de cego extralúcido" (DERRIDA, 2002: 16), ou ainda como um "olhar sem fundo" e "completamente outro" (DERRIDA, 2002: 30), resiste à transformação em um mero reflexo, em um objeto de reflexão, e não cessa de exaltar sua irredutível opacidade. Se lido como uma escrita das aventuras do olhar, como uma meditação sobre a estranha reflexividade manifesta nas experiências do "sentir-se nu" e do "saber-se pudico" e como uma admiração amorosa perante a resistência do olhar do outro, $O$ animal que logo sou (A seguir) lança questionamentos irrequietos à estética enquanto uma teoria do conhecimento sensível. Transformada no centro ótico da reflexão, a obscenidade da primeira pessoa colocada a nu perante o animal (e perante o leitor) não apenas subverte a validez da distância estética, mas faz do sentimento (do afeto, da experiência) da nudez (e não do belo, por exemplo) o "próprio" do homem. A desterritorialização da aurora do conhecimento para o espaço de um banheiro confunde irremediavelmente as fronteiras entre natureza e cultura. Colocando em cena a nudez e a vergonha e enfatizando dessa maneira a importância das emoçôes e do corpo (e não apenas da imaginação e da cogniçâao), o texto derridiano descreve uma estética do animal-estar: uma manifestaçáo do pensamento confuso na materialidade sensível, um saber que é um risco por ser um afeto e uma paixão. Assim, pela abolição da distância e pela confusão de territórios, o animal-estar leva a uma exacerbaçáo do componente "sensível" na expressão “conhecimento sensível”.

\section{Referências bibliográficas}

ATWOOD, Margaret. A Porta. Trad. Adriana Lisboa. Rio de Janeiro: Rocco, 2013. BELLESSI, Diana. Tener lo que se tiene. Poesía reunida. Buenos Aires: Adriana Hidalgo, 2009.

COETZEe, J. M. Elizabeth Costello. New York: Penguin, 2003. 
COLETTE. Les Vrilles de la vigne. Paris: Le Livre de Poche, 2011. . La Chatte. Paris: Hachette, 2004.

DERRIDA, Jacques. $O$ animal que logo sou (A seguir). Trad. Fábio Landa. São Paulo: UNESP, 2002.

GAUTIER, Théophile. Romans, contes et nouvelles. Paris: Gallimard, 2002.

GOMBROWICZ, Witold. Dziennik 1953-1958. Kraków: Wydawnictwo Literackie, 1997.

HAHN, Kimiko. Toxic Flora. New York: W.W. Norton \& Company, 2010.

KORSMEYER, Carolyn. Gender and Aesthetics. An Introduction. New York: Routledge, 2004.

LISPECTOR, Clarice. Laços de família. Rio de Janeiro: Rocco, 1998.

NAIR, Anita. Le chat karmique. Trad. Marielle Morin. Paris: Picquier, 2005.

RAMOS, Nuno. Cujo. São Paulo: Editora 34, 2011.

POŚWIATOWSKA, Halina. Wszystkie wiersze. Kraków: Wydawnictwo Literackie, 2012.

SZYMBORSKA, Wisława. Poemas. Trad. Regina Przybycien. São Paulo: Companhia das Letras, 2012. . Nic dwa razy. Kraków: Wydawnictwo Literackie, 1997.

TANIZAKI, Junichiro. Em louvor da sombra. Trad. Leiko Gotoda. São Paulo: Companhia das Letras, 2007.

Olga Guerizoli Kempinska possui graduação e mestrado em Filologia Românica pela Uniwersytet Jagiellonski de Cracóvia e doutorou-se em História Social da Cultura pela PUC-Rio. Atualmente é professora de Teoria da Literatura no Departamento de Ciências da Linguagem da Universidade Federal Fluminense. Publicou em 2011 o livro Mallarmé e Cézanne: obras em crise. Tem experiência na área de Letras, com ênfase em Teoria da Literatura, atuando principalmente nos seguintes temas: estética da recepção, relação entre mímesis e emoções, poéticas do trans- e multilinguismo. E-mail: <olgagkem@gmail.com> 
ERRATA

No artigo "Estéticas do animal-estar" publicado no periódico Alea: Estudos Neolatinos, $17(1):<127-138>$, na página $<127>$ :

Onde se lia: "KEMPISKA"

Leia-se: "<KEMPINSKA>"

No rodapé das páginas 127-138:

Onde se lia: "OLGA KEMPISKA | Estéticas do animal-estar"

Leia-se: "OLGA KEMPINSKA | Estéticas do animal-estar"

No Sumário e no Contents:

Onde se lia: "OLGA KEMPISKA"

Leia-se: "OLGA KEMPINSKA" 